\title{
Transition of Deformation Structures in Ni and Au by D-T Neutron Irradiation*
}

\author{
By A. Okada**, K. Kanao***, T. Yoshiie** \\ and S. Kojima**
}

\begin{abstract}
The process of the deformation structure development was investigated for $\mathrm{Ni}$ and $\mathrm{Au}$ irradiated to various fluence levels with D-T neutrons. In Ni irradiated to fluences ranging from 1 to $10 \times 10^{21} \mathrm{n} / \mathrm{m}^{2}$, and in $\mathrm{Au}$ from 0.5 to $5 \times 10^{21} \mathrm{n} / \mathrm{m}^{2}$, the transition in the deformation process from dislocation channeling to deformation by cell formation was observed with increase in the amount of deformation. In the specimens for fluences lower than the minimum fluence of these ranges, the deformation by cell formation was observed to continue until the specimen broke, while the deformation by dislocation channeling for fluences higher than the maximum fluence. The diagram for the deformation structure transition can be illustrated as a function of irradiation fluence and deformation amount.

The difference in the deformation structures of neutron irradiated $\mathrm{Au}$ and $\mathrm{Ni}$ can be interpreted in terms of the difference in the stacking fault energy. The shape of the stress-strain curves and material ductility were also discussed correlating to the deformation structures.
\end{abstract}

(Received December 1, 1988)

Keywords; neutron irradiation, deformation mode, deformation structure, dislocation channel, miniaturized tensile test, stress-strain curve, irradiation hardening

\section{Introduction}

The miniaturization technique of tensile testing $^{(1)(2)}$ is very practical for the investigation of the correlation between the mechanical property changes and deformation structure changes. Using this technique, the microstructure of the specimen after applying a designed amount of deformation can be observed without any paticular preparatory process for the preparation of specimen such as specimen slicing which may bring about mechanical damages. By this technique, the present authors have investigated the correlation among the defect structure, deformation structure and mechanical property change for neutron-irradiated $\mathrm{Au}, \mathrm{Ni}$ and $\mathrm{Fe}^{(3)-(5)}$.

Neutron irradiation produces a large variety

* Partly in Japan-USA Cooperation Program on Collaboration in the RTNS-II Utilization sponsored by Monbusho (The Japanese Ministry of Education, Science and Culture).

** Faculty of Engineering, Hokkaido University, Sapporo 060, Japan.

*** Graduate Student, Hokkaido University. Present address: Nippon Denso Co. Ltd., Kariya 448, Japan. of defect structures in metals ${ }^{(6)(7)}$ and these structure varies widely depending on the irradiation conditions. The different defect structures will cause different deformation processes such as dislocation channeling ${ }^{(8)}$.

In order to investigate the correlation between the deformation structures and mechanical property, tensile tests and structure observation were carried out on $\mathrm{Ni}$ and Au using miniaturized tensile specimens irradiated with D-T neutrons from RTNS-II.

\section{Experimental Procedures}

\section{Specimens}

Miniaturized tensile specimens were prepared from $\mathrm{Ni}$ of $99.99 \%$ purity and $\mathrm{Au}$ of 99.999\% purity. These specimens were prepared by punching from the cold rolled sheets with $0.2 \mathrm{~mm}$ thickness. After punching, $\mathrm{Ni}$ and $\mathrm{Au}$ were annealed in vacuum for $1.8 \mathrm{ks}$ at 1170 and $770 \mathrm{~K}$, respectively. The dimensions of the miniaturized specimen were 12.5 $\mathrm{mm}$ long and $2.3 \mathrm{~mm}$ wide with gage section $1.2 \mathrm{~mm} \times 5.5 \mathrm{~mm}$. 


\section{D-T neutron irradiation}

Specimens were irradiated with D-T neutrons from the Rotating Target Neutron Source (RTNS-II) at Lawrence Livermore National Laboratory. The irradiation was carried out up to $4 \times 10^{22} \mathrm{n} / \mathrm{m}^{2}$ at $300 \mathrm{~K}$ by arranging specimens systematically at locations with various neutron flux densities in the irradiation capsule. The ratio of the highest to the lowest neutron flux density in the capsule was larger than 2 orders.

\section{Tensile tests and structure observations}

Tensile tests were performed at $300 \mathrm{~K}$, at a strain rate of $5 \times 10^{-4} \mathrm{~s}^{-1}$. The optical and TEM observations were conducted on these specimens after applying a designed amount of deformation, 2 and $5 \%$, and up to the limit of the uniform elongation. The TEM specimen was prepared from the parallel portion $(1.2$ $\mathrm{mm}$ wide) of the tensile specimen by electrolytical thinning. The development of the slip pattern in the identical area on the specimen surface was successively observed with an optical microscope with a special mount on which the specimen is deformed by rotating a spindle of a micrometer.

\section{Experimental Results and Discussion}

\section{The dependences of the stress-strain behavior of $\mathrm{Ni}$ and $\mathrm{Au}$ on the neutron fluence}

The dependences of the stress-strain behavior of $\mathrm{Ni}$ and $\mathrm{Au}$ on the neutron fluence are shown in Fig. 1(a) and (b), respectively.

\section{(1) Nickel}

As is shown in Fig. 1(a), with increase in the fluence the yield stress increased and the uniform elongation limit decreased to almost a half of the unirradiated specimen. These curves show that the stress levels where the uniform elongation terminates are almost the same for both unirradiated and irradiated specimens. This result suggests that the ultimate tensile strength of the irradiated specimens is limited to that of the unirradiated specimens. As far as the yield stress of the irradiated specimens is lower than the stress level at the work hardening limit in tensile deformation, the ultimate strength may depend on the uniform elongation limit because this is controlled by the work hardenability. In this case, the stress strain curves of the irradiated specimens can be regarded as the second half curves of an unirradiated specimen whose first half is cut off at a stress level corresponding to the yield stress of the irradiated specimen, as

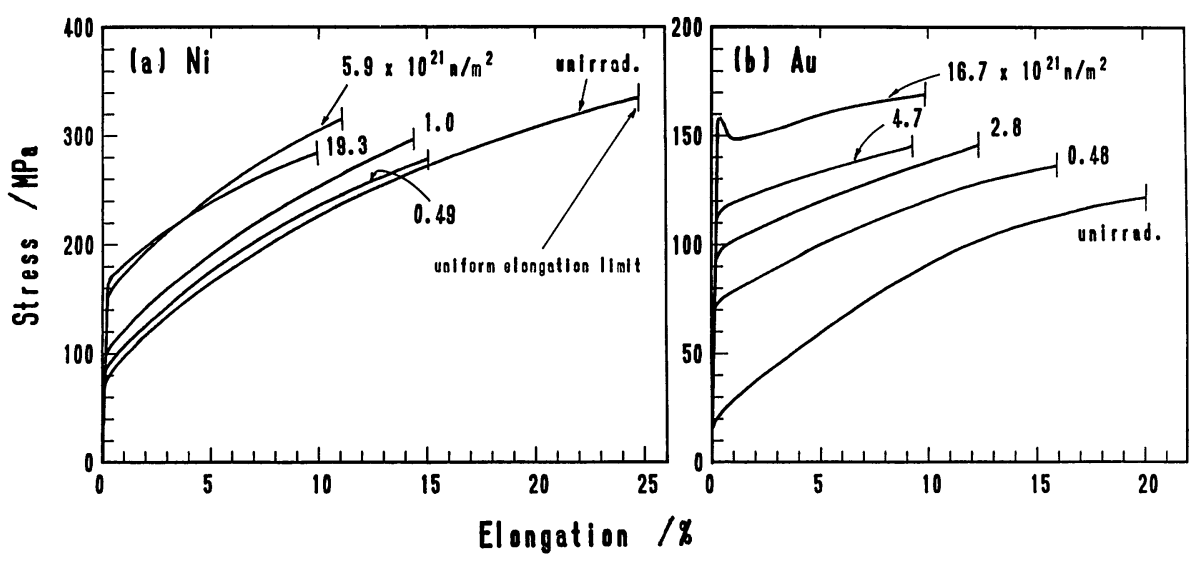

Fig. 1 Stress-strain curves for D-T neutron irradiated Ni and Au. Large amount increase in the yield stress and loss in the ductility are seen. 
shown later. This is equivalent to reloading the annealed specimen after applying a certain amount of deformation.

\section{(2) Gold}

At relatively lower fluences, the change of the stress-strain curves of $\mathrm{Au}$ is almost the same as that of $\mathrm{Ni}$ as seen in Fig. 1(b). At higher fluences, the first half of the curves disappeared, so their strain hardening becomes much more moderate than in $\mathrm{Ni}$ and the yield drop appeared. For the highest fluence in the present experiment, the yield stress exceeds the ultimate tensile stress (true stress) of the unirradiated $\mathrm{Au}$ and the uniform elongation limit rather increased in contrast to the expectation. In general, the uniform elongation limit can be roughly estimated from the slope of the stressstrain curve, i.e., if the flow stress $\sigma$ is presented by $\sigma=k$ (strain) ${ }^{n}$, where $k$ is a constant, the uniform elongation limit is equal to strain hardening exponent, $n$. Thus, the smaller elongation limit should be expected from smaller work hardening exponent. The mismatch with this expectation in $\mathrm{Au}$ is the most marked difference in the curves of $\mathrm{Ni}$, and is discussed in the later section.

\section{Defect structures of irradiated specimens}

(1) Nickel

Very small defect clusters of 0.5 to $3 \mathrm{~nm}$ can be seen as in Fig. 2. These small clusters are classified into two groups; clusters larger than $2 \mathrm{~nm}$ are interstitial type dislocation loops and other smaller clusters are stacking fault tetrahedra (SFT). The number of these clusters increased linearly with increase in the neutron fluence, and their number density was $3 \times 10^{22} / \mathrm{m}^{3}$ at $1 \times 10^{21} \mathrm{n} / \mathrm{m}^{2}$.

\section{(2) Gold}

In irradiated specimens, SFT with a mean size of $1.5 \mathrm{~nm}$ and a smaller number of large interstitial type dislocation loops about 4 to $8 \mathrm{~nm}$ in diameter are observed as shown in Fig. 3. The number of these defect clusters also is proportional to the neutron fluence in the same manner as $\mathrm{Ni}$, and their number density was $2 \times 10^{22} / \mathrm{m}^{3}$ at $1 \times 10^{21} \mathrm{n} / \mathrm{m}^{2}$.

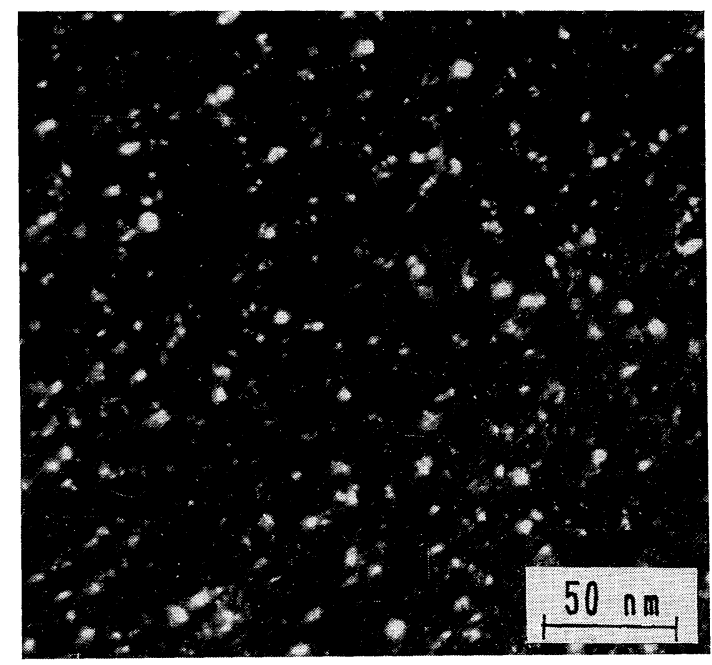

Fig. 2 Defect structures of $\mathrm{Ni}$ irradiated with D-T neutrons. Smaller defect clusters are SFT and larger ones are interstitial dislocation loops.

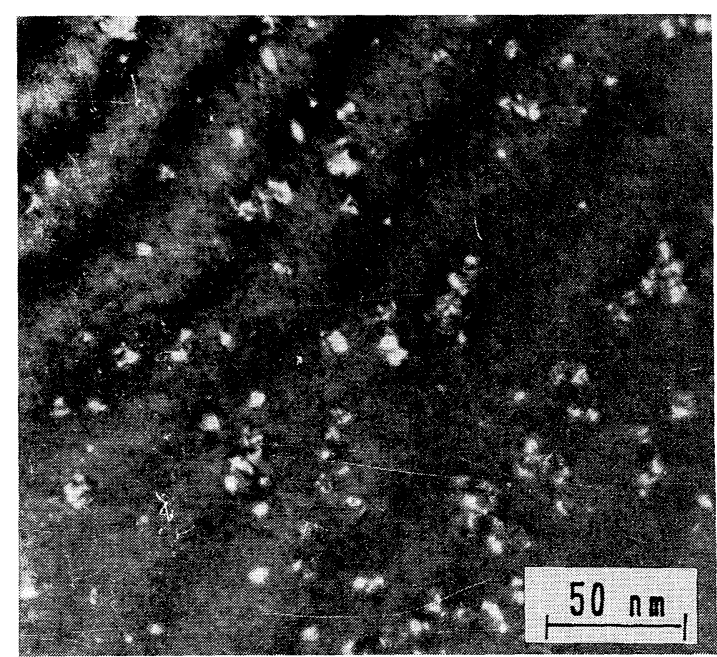

Fig. 3 Defect structures of $\mathrm{Au}$ irradiated with D-T neutrons. Smaller defect clusters are SFT and larger ones are interstitial dislocation loops.

\section{Variation of lightly deformed structure with fluence}

The deformation patterns on the surface and the dislocation structures of $\mathrm{Ni}$ and $\mathrm{Au}$ were observed with optical and electron microscopes, respectively, after applying a light tensile deformation of $2 \%$. 


\section{(1) Nickel}

The surface slip patterns and dislocation structures are shown in Figs. 4 and 5, respectively. In the unirradiated specimen, a well developed cell structure could be observed by electron microscopy without showing any detectable slip traces on its surface. No remarkable slip traces could be still observable for the specimen irradiated up to $5 \times 10^{20}$ $\mathrm{n} / \mathrm{m}^{2}$. During this stage of the deformation, the cell size became smaller and dislocations tended be parallel to the slip plane with increase in the fluence. The formation process of the dislocation arrays parallel to slip planes continued at higher fluences, and widely spaced slip bands became observable at a fluence about $10^{21} \mathrm{n} / \mathrm{m}^{2}$. For the specimens irradiated higher than $10^{22} \mathrm{n} / \mathrm{m}^{2}$, slip patterns became more distinct with many crossings, and their corresponding dislocation structure was composed of well developed dislocation channels. However, not all of the dislocation channels which were observed by the electron microscopy could be seen with sharp contrast on the specimen surface. This is the same in $\mathrm{Au}$.

A very clear transition of deformation mode from the homogeneous deformation forming cellular structure to the highly locallized deformation by dislocation channeling was observed.

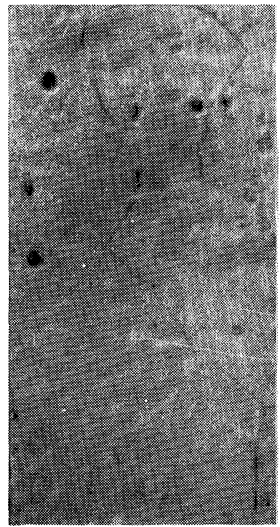

unirrad.

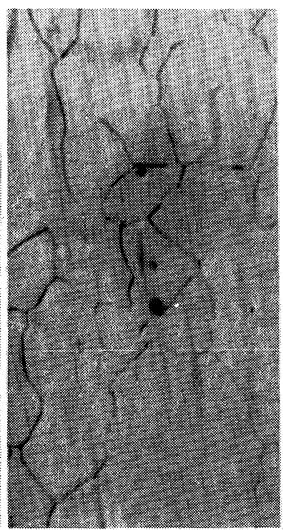

0.10

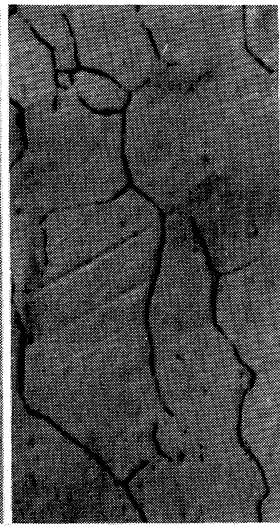

0.24

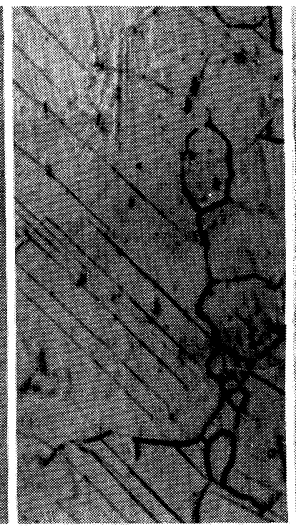

0.83

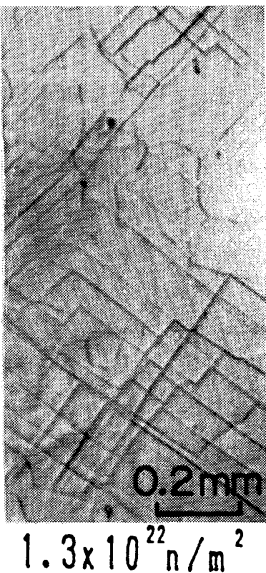

Fig. 4 Slip patterns of Ni deformed $2 \%$ in tension. Slip lines with sharp contrast is obvious for higher fluences.

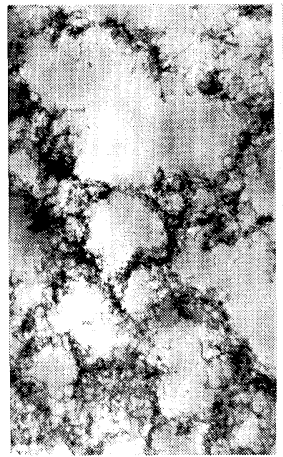

unirrad.

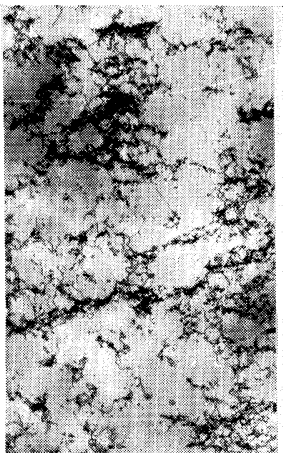

0.10

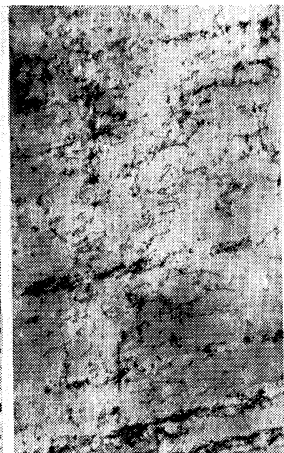

0.24

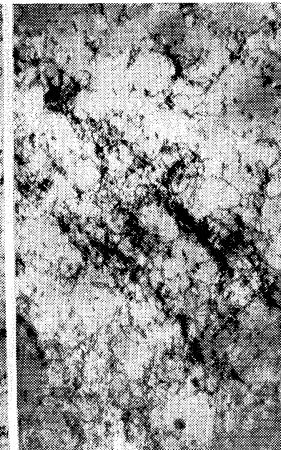

0.83

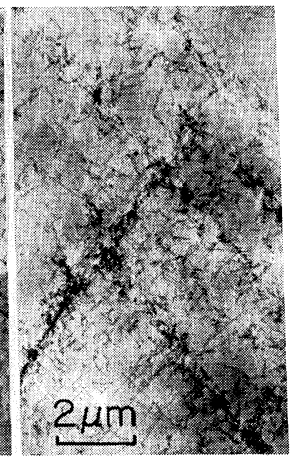

$1.3 \times 10^{22} \mathrm{n} / \mathrm{m}^{2}$

Fig. 5 Deformation dislocation structures of Ni deformed $2 \%$ in tension. Transition from cell structure to dislocation channel is observed with increase in fluence. 


\section{(2) Gold}

As seen in Fig. 6, the surface of the unirradiated $\mathrm{Au}$ after deformed $2 \%$ was covered with uniformly distributed wavy slip lines. These slip lines tended to gather to form clusters with increase in the fluence up to $0.3 \times 10^{21} \mathrm{n} / \mathrm{m}^{2}$. For the fluence higher than this level, sharp zig-zag slip lines developed with spacing of a few $\mu \mathrm{m}$. The dislocation cell size decreased from $1 \mu \mathrm{m}$ of the unirradiated specimen to $0.5 \mu \mathrm{m}$ of that irradiated with $0.5 \times 10^{21} \mathrm{n} / \mathrm{m}^{2}$. In the specimens irradiated to higher fluences $\left(1-8 \times 10^{21} \mathrm{n} / \mathrm{m}^{2}\right)$, whose surface was covered with zig-zag slip lines with both sharp and faint contrasts, the dislocation channels were clearly observed and dislocations were seen only in the intersection of the channels as seen in Fig. 7. Except for these areas, almost no dislocations and no defect clusters (SFT) could be observed in the channel. No change in the irradiation induced defect structure by deformation could be observed outside of the channels.

The deformation structures of the dislocation channels containing few dislocations in $\mathrm{Au}$ makes a contrast to the structures containing dense dislocation tangles in both the channels and the matrix in Ni. This corresponds to

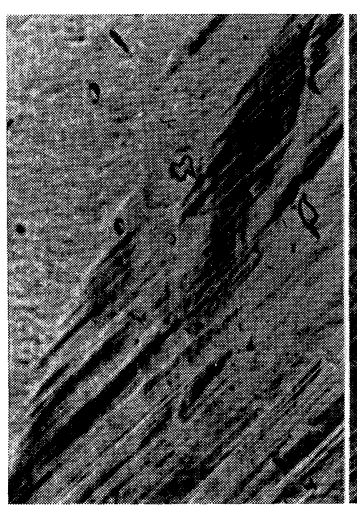

0.5

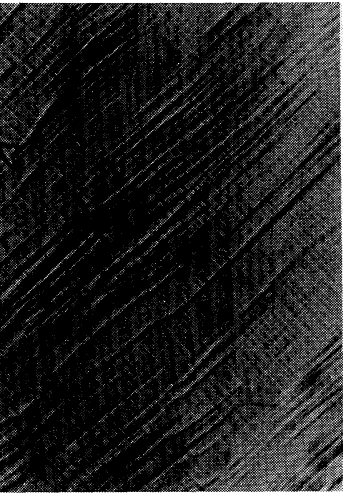

0.9

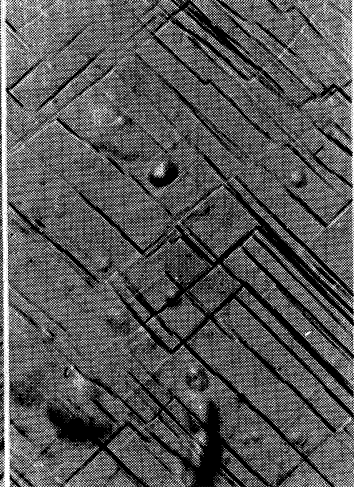

2.8

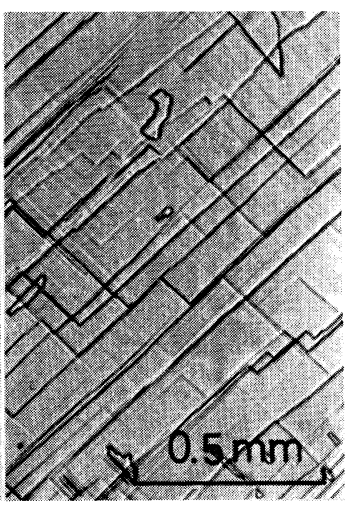

$11 \times 10^{21} \mathrm{n} / \mathrm{m}^{2}$

Fig. 6 Slip patterns of Au deformed $2 \%$ in tension.

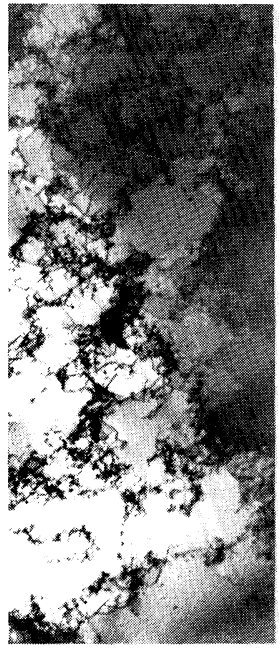

unirrad.

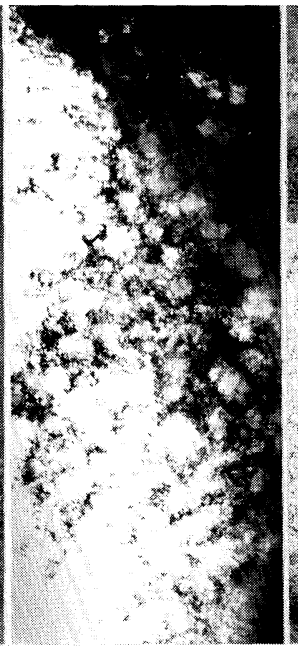

0.5

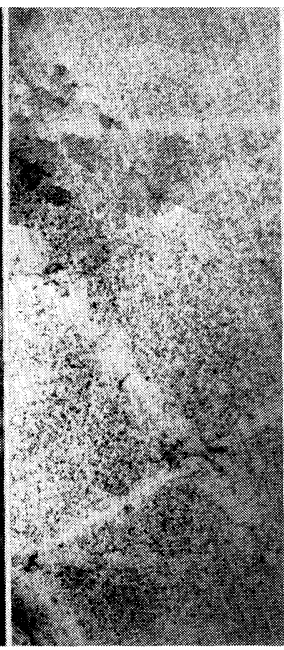

1

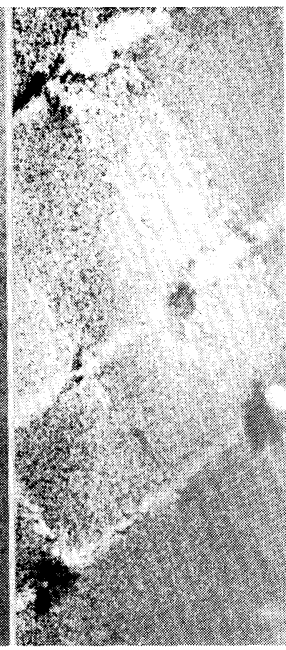

3

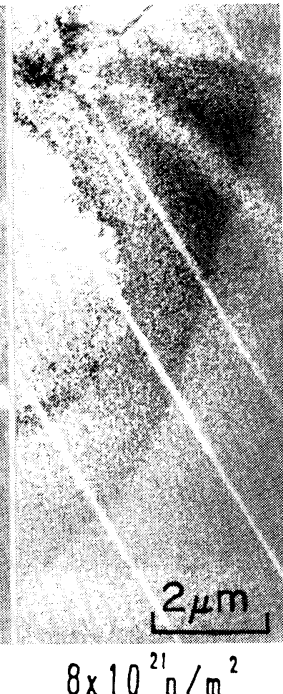

$8 \times 10^{21} \mathrm{n} / \mathrm{m}^{2}$

Fig. 7 Deformation dislocation structures of Au deformed $2 \%$ in tension. 
the observation that the smaller work hardening was seen during channeling deformation in the Au compared with Ni.

\section{Deformation structures at large amounts of deformation}

The identical area of the surface was successively observed with an optical microscope by increasing deformation for Au irradiated to $1.1 \times 10^{22} \mathrm{n} / \mathrm{m}^{2}$. In the specimens irradiated to this fluence, the dislocation channeling process was observed until they were broken. The spacing of slip lines was $60 \mu \mathrm{m}$ in uniformly elongated portion, and $40 \mu \mathrm{m}$ in the portion close to the fractured edge.

The change in the spacing of dislocation channel for the deformation can be considered to follow a hyperbolic curve as shown in Fig. 8 , and the contrast and width of the channel remained almost unchanged until the specimen broke. These results show that the plastic deformation amount is proportional to the reciprocal of the spacing of dislocation channel (i.e., the number density of the channel), and a new dislocation channel is created successively after a limit number of dislocations glide in the channel.

The optical and electron microscopic observations show that there are two deformation modes in the irradiated specimens. One is the usual deformation process in which uniform slip takes place to form a cell structure. Another one is the dislocation channeling deformation in which the development of widely spaced slip lines is observed with an optical microscope as mentioned above. In the

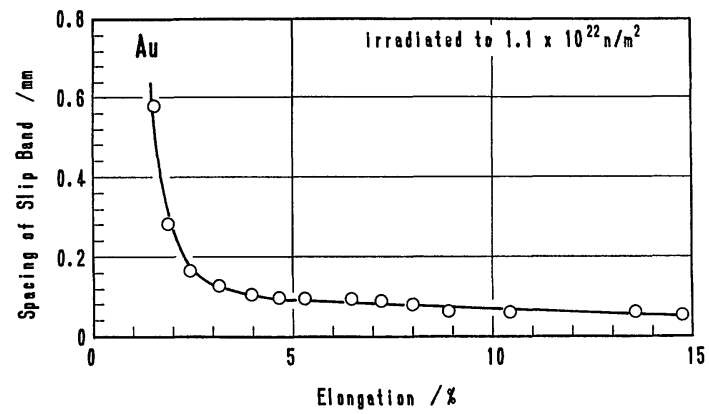

Fig. 8 Variation of channel spacing as a function of deformation amount. Elongation is proportional to the reciprocal of slip band spacing. specimen irradiated to a lower fluence, only the usual deformation mode was observed until the specimen broke. While in the specimens irradiated to a higher fluence, the deformation is initiated by dislocation channeling and at a larger deformation this deformation mode changes to the cell formation. The deformation amount where this transition takes place depends on the degree of the irradiation fluence. The higher the irradiation fluence makes the larger the deformation amount for the transition. The same type of deformation mode change as in Au was observed in Ni. The development of the slip pattern is not obvious in the $\mathrm{Ni}$ specimens for lower fluences.

\section{A diagram for the deformation mode transition}

The observations of the deformation structure change in $\mathrm{Au}$ and $\mathrm{Ni}$ were conducted at various amounts of deformation, viz., 2 and $5 \%$, and at the uniform elongation limit (around 10\%) for specimens irradiated to various fluence levels. The structures developed at the uniform elongation limit were observed for the uniformly elongated part of the broken specimen.

A diagram for the deformation mode transition at a fluence and a deformation amount is depicted as shown in Fig. 9(a) and (b). These diagrams show that the deformation mode transition from the dislocation channeling to the usual slip with the formation of the dislocation cell structure takes place before fracture for the neutron fluences ranging from $0.5 \times 10^{21}$ to $5 \times 10^{21} \mathrm{n} / \mathrm{m}^{2}$ in $\mathrm{Au}$, and from $1 \times 10^{21}$ to $10 \times 10^{21} \mathrm{n} / \mathrm{m}^{2}$ in $\mathrm{Ni}$. The cell size is also shown in the figure.

\section{Deformation mechanism of irradiated $\mathrm{Ni}$ and $\mathrm{Au}$}

The general feature of the stress-strain curves for irradiated metals relating to the deformation mode change, can be discussed by using the scheme as shown in Fig. 10. Let the fracture stress level of the unirradiated metal be $\sigma_{\max }$ (viz., this corresponds to the limit of work hardening in tensile deformation). If the yield stress of the irradiated metal is smaller than $\sigma_{\max }$ because of the lower fluence irradia- 

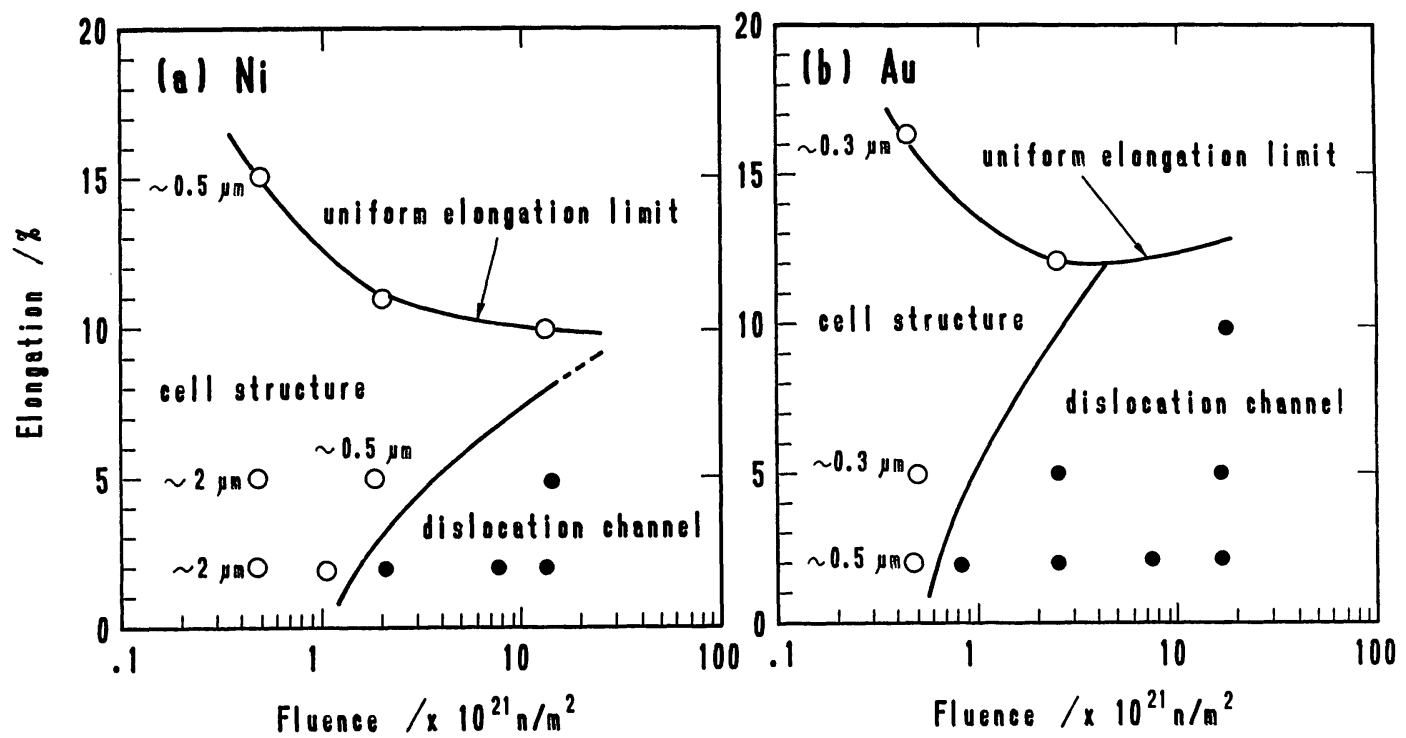

Fig. 9 Deformation mode transition diagram for $\mathrm{Ni}$ and $\mathrm{Au}$. Open circles; cell formation, and closed circles; dislocation channeling deformation.

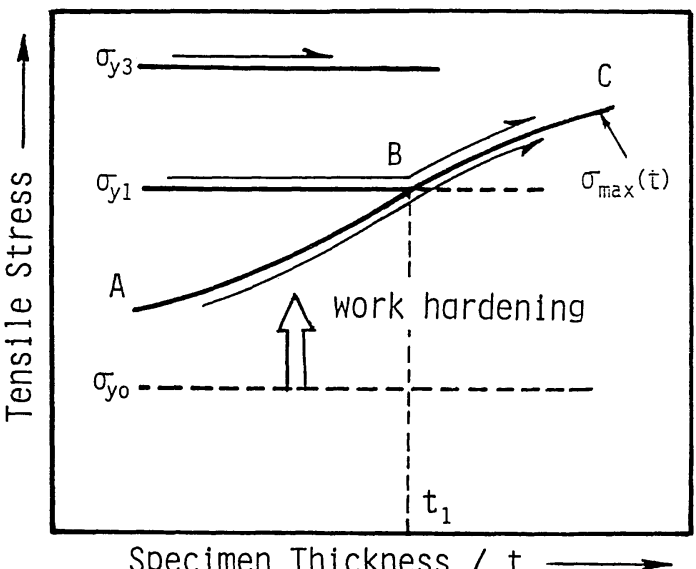

Fig. 10 Scheme for the deformation mode transition in neutron irradiated metal. Specimens whose yield stress $\left(\sigma_{\mathrm{y} 0}\right)$ is lower than $\sigma_{\max }$ can be work hardened and their $\sigma_{\mathrm{uts}}$ is given by curve A-B-C for corresponding thickness. While in case $\sigma_{\mathrm{y} 0}<\sigma_{\max }, \sigma_{\mathrm{uts}}$ changes along $\sigma_{\mathrm{y} 1}-\mathrm{B}-\mathrm{C}$.

tion, the flow stress can increase up to $\sigma_{\max }$ with increase in the deformation amount through the work hardening process. This work hardeing process will start after the channeling deformation finishes and this process may be different from that of unirradiated metals due to the existence of the defect clusters and the dislocation channels already formed by the leading process. Although the initial condition of the deformed structure is different by irradiation fluence, the shape of the second half of the stress-strain curves after yielding is almost unchanged. This suggests that the increase in the flow stress by defect clusters in the irradiated specimens is equivalent to the work hardening in the unirradiated specimens. However, it cannot be explained at present why the stress strain curves in the irradiated specimens trace the second half of the curves of the unirradiated specimens.

On the other hand, when the highly irradiated specimens whose yield stress is larger than $\sigma_{\max }$ is deformed in tension, they cannot be work hardened any more by the tensile deformation, i.e., by forming dislocation cells, because their whole volume is already much more hardened by the irradiation. In these specimens, the dislocations will only glide by forming the dislocation channeling, which requires the large stress concentration enough to eliminate the defect clusters.

After a certain number of dislocations slip, a larger stress must be needed to move glide dislocations against the back stress from the 
piled-up dislocations at the ends of the channels at grain boundaries, or from some other process such as the initiation of secondary $\operatorname{slip}^{(9)}$. Then another new channel must be created for additional deformation. In this deformation process, until the crossings among dislocation channels take place the flow stress increment may be smaller, because the dislocations can slip without cutting each other in the channel. The moving out of the dislocations from the channel is difficult in low stacking fault energy metals such as $\mathrm{Au}\left(\sim 1 \times 10^{-2}\right.$ $\mathrm{J} / \mathrm{m}^{2}$ ), however it may be easy in metals of high stacking fault energy such as $\mathrm{Ni}\left(\sim 8 \times 10^{-2} \mathrm{~J} / \mathrm{m}^{2}\right)$. The difference in the easiness of the moving out of the dislocations from the channels corresponds to the work hardening rate and the deformation dislocation structures. In low stacking fault energy metals, the interaction among dislocations on parallel slip planes in a channel may be smaller, because the cross slip is difficult to take place. This agrees with the observations that few dislocation tangles remained in the channels except for the intersections of the channels in $\mathrm{Au}$, as is seen in Fig. 5.

Therefore, the deformation mode transition from the usual slip deformation to the dislocation channel deformation suggests that the conventional criterion for the ductility, i.e., the uniform elongation limit is estimated from the work hardening exponent, becomes no more valid for channeling deformation in highly irradiated metals.

\section{Conclusion}

The deformation structure change in the D$\mathrm{T}$ neutron irradiated $\mathrm{Ni}$ and $\mathrm{Au}$ deformed at $300 \mathrm{~K}$ was investigated with an electron microscope by using miniaturized tensile specimens after applying a designated amount of deformation. The development of surface pattern by increasing deformation was successively observed under the optical microscope. The results obtained were summarized as follows.

(1) The transition of the deformation process from the dislocation channeling to that by cell structure formation took place in the specimens irradiated to the fluences ranging from 1 to $10 \times 10^{21} \mathrm{n} / \mathrm{m}^{2}$ in $\mathrm{Ni}$ and 0.5 to $5 \times 10^{21} \mathrm{n} / \mathrm{m}^{2}$ in Au.

(2) In the specimens irradiated to the fluences lower and higher than these levels, the deformation by the formation of the dislocation channels and dislocation cells continues, respectively, until the specimen breaks.

(3) Deformation mode transition diagram can be illustrated as a function of the deformation amount and the irradiation fluence.

(4) The difference in the deformation structures between $\mathrm{Au}$ and $\mathrm{Ni}$, especially in the feature of dislocation channel can be understood as a results from the difference in the stacking fault energy.

\section{Acknowledgments}

The authors are grateful to Professors K. Kawamura and K. Sumita for organizing the program and to Drs. D. Short and H. Heikkinen of LLNL for their great help in the D-T neutron irradiation procedure. They are also grateful to Oarai Branch for JMTR Utilization of Tohoku University for facilitating the postirradiation experiments.

\section{REFERENCES}

(1) For example, The Use of Small-Scale Specimens for Testing Irradiated Material, ASTM Special Technical Publication 888, W. R. Corwin and G. E. Lucas ed., (1986). Phil., Pa.

(2) A. Kohyama and N. Igata: J. At. Energy Soc. Japan, 25 (1983), 329.

(3) A. Okada, T. Yoshiie, S. Kojima and M. Kiritani: J. Nucl. Mater., 141-143 (1986), 907.

(4) A. Okada, T. Yoshiie, S. Kojima and M. Kiritani: Proc. XI Int. Cong. on Electron Microscopy, Kyoto, (1986), 1279.

(5) A. Okada, K. Kanao, Y. Satoh, S. Kojima, T. Yoshiie and M. Kiritani: J. Nucl. Mater., 154-156 (1988), 1301.

(6) M. Kiritani: J. Nucl. Mater., 133 \& 134 (1985), 85.

(7) M. Kiritani: J. Nucl. Mater., 137 (1986), 261.

(8) S. Kitajima and K. Shinohara: Proc. 8th Int. Symp. on Metallurgy and Materials Science (1987), p. 373, and Bulletin of the Japan Inst. Metals, 27 (1976), 675.

(9) S. Kitajima and K. Shinohara: J. At. Energy Soc. Japan, 30 (1988), 663. 